\title{
Empresas municipais de desporto: contributos para a sua caracterização legal, funcional e relacional
}

\author{
Maria José Carvalho ${ }^{1}$ \\ José Cancela Moura \\ Nancy Oliveira ${ }^{2}$
}

\author{
${ }^{1}$ Faculdade de Desporto \\ Universidade do Porto \\ Portugal \\ ${ }_{2}^{2}$ Proviver/Câmara Municipal de Vilaverde \\ Portugal
}

\section{RESUMO}

O presente trabalho aborda uma temática pouco explorada e pesquisada no sector desportivo e que se configura, actualmente, de extrema importância para o desenvolvimento e para a gestão do Desporto ao nível local.

Vocacionados, por razões de ordem operacional e de investigação, para a problemática da caracterização e funcionamento das estruturas organizativas que gravitam à volta do Desporto, são objecto de análise neste estudo as empresas municipais que no seu código de actividade económica contemplem o desporto. Determinamos como objectivo principal deste trabalho, caracterizar estas entidades do sector empresarial local no que respeita ao seu enquadramento legal e funcional, e quanto a este último, designadamente, a sua dimensão, localização, volume de negócios, número de trabalhadores e código de actividade económica principal.

Estas empresas surgiram nos municípios portugueses, com maior intensidade na última década, como uma nova cultura de gestão de diversas áreas, nomeadamente da gestão do desporto, tendo a sua organização e enquadramento legal sido recentemente alvo de alterações significativas por via da publicação do Regime Jurídico do Sector Empresarial Local, Lei 53-F/2006, de 29 de Dezembro, diploma que constituirá o cerne essencial de análise no presente trabalho.

Palavras-chave: empresas municipais, organizações desportivas, município

\begin{abstract}
Municipal enterprises of sport: contributions to the legal, functional and relational characterization

The present work approaches a thematic that is not commonly explored and researched in sport sector, although its extreme importance for the development and management of Sport at the local level.

Since we are devoted to the problem of characterization and functioning of the organizational structures that surround sport, the scope of the present work is the set of municipal enterprises that consider sport in their code of economic activity.

The main objective of our work is to characterize these entities, which are considered as local enterprises, regarding their legal and operational framework, particularly their size, location, turnover, labour force and main code of economic activity.

These companies became more and more frequent in the Portuguese municipalities during the last decade, as a new culture of management in various areas, namely in sports management, whose organizational and legal framework recently suffered significant changes due to the publication of the Legal Framework for the Local Enterprise Sector, Law 53-F/2006, of 29 of December. This law will be in the core of our analysis in the present work.
\end{abstract}

Key-words: municipal enterprises, organizational structures, municipality 


\section{INTRODUÇÃO}

Já é um lugar-comum afirmar que as Autarquias Locais são das entidades com uma intervenção mais assinalável na estrutura global do sistema desportivo e, actualmente, as principais financiadoras do associativismo e da própria actividade desportiva.

Daí a importância que as mesmas revestem actualmente e podem continuar a exercer nos âmbitos do fomento e desenvolvimento do desporto.

E esta importância decorre precisamente da incumbência aos Municípios da concretização do princípio constitucional do direito ao desporto, ao se entender que eles são parte integrante do próprio Estado(3). Na esteira da Carta Internacional da Educação Física e do Desporto da UNESCO e da Carta Europeia do Desporto, rege em Portugal, o artigo 79..$^{\circ}$ da Constituição da República Portuguesa que é peremptório quanto à universalidade do desporto e à função da Administração Pública no seu fomento e desenvolvimento:

“(...) incumbe ao Estado, em colaboração com as escola e as associações e colectividades desportivas, promover, estimular, orientar e apoiar a prática e a difusão da cultura física e do desporto (...).

Acção esta, considerada como tarefa fundamental do Estado de acordo com o que se encontra vertido no artigo $9^{\circ}$, alínea d), parte final, deste mesmo texto constitucional.

Igualmente na regulamentação específica destas autoridades locais o desporto é contemplado como uma das atribuições da Câmara Municipal, conforme o estatuído no artigo $64 .^{\circ}$, n. $^{\circ} 4$, alínea b), da Lei n ${ }^{\circ}$ 169/99, de 18 de Setembro:

(...) apoiar ou comparticipar, pelos meios adequado, no apoio às actividades de interesse municipal, de natureza social cultural, desportiva, recreativa ou outra (...).

À tradicional orgânica das autarquias locais enquanto instâncias de uma complexa estrutura da organização do poder político e da administração, mas que consubstanciam formas autónomas de corresponder às necessidades das populações locais, introduziu-se nos últimos anos uma figura organizacional que se configura como um instrumento privilegiado de gestão autárquica.

Este novo sujeito de gestão pública municipal, a empresa municipal, apesar de, pelo menos, desde a lei das autarquias locais de 19771 ter tido acolhimento e autorização expressa por parte do legislador, só após 1998 se afirmou e expandiu com impacto crescente. Contudo, a Lei n. ${ }^{\circ}$ 58/98, de 18 de Agosto, Lei-Quadro das Empresas Municipais, Intermunicipais e Regionais, como salienta Pedro Gonçalves $^{2}$, padecia de defeitos e ambiguidades, por exemplo, quanto à natureza jurídica das empresas, à ausência de determinações claras sobre os limites do respectivo objecto (facto que conduziu à criação de empresas sem objecto empresarial, para o exercício de funções administrativas ou, por exemplo, para se ocuparem da "gestão de parques desportivos" compostos por um campo de futebol e um pavilhão desportivo), a ausência de definição rigorosa das condições de viabilidade económica das empresas a constituir (o que conduziu à criação de empresas inviáveis), a total omissão de regras sobre a escolha de parceiros privados ou a ausência das exigência geral de um quadro de regulação contratual entre a empresa e o município (6). Assim se justifica que passados oito anos este regime tenha sido revogado com a publicação da Lei n. ${ }^{\circ}$ 53-F/2006, de 29 de Dezembro, denominada Regime Jurídico do Sector Empresarial Local (RJSEL) ${ }^{3}$, que como é propalado em seu abono, agiliza procedimentos, permite maior flexibilidade da gestão, possibilita recrutamento de técnicos qualificados, e promove a especialização de tarefas e adopção de instrumentos, mais eficientes, de direito privado para a prossecução dos objectivos estatutários, colocando o Município ao nível de uma qualquer sociedade comercial na área dos serviços, ressalvando que: (...) Não podem ser criadas, ou participadas, empresas de âmbito municipal, intermunicipal, ou metropolitano cujo objecto social não se insira no âmbito das atribuições da autarquia (...) sendo proibida a criação de empresas para o desenvolvimento de actividades de natureza exclusivamente administrativa ou de intuito predominantemente mercantil ${ }^{4}$. Por conseguinte, dadas as limitações impostas para este trabalho, será sobretudo neste diploma que centraremos a nossa análise jurídica, no que respeita a aspectos que consideramos essenciais para a operacionalização e funcionalidade sobretudo das empresas municipais, finalizando com uma caracterização sumária dos principais traços fisionómicos destas entidades existentes no sector do desporto.

\section{MATERIAL E MÉTODOS}

A norma pública é o principal instrumento utilizado para a interpretação jurídica do regime das empresas 
municipais. Não descurando a abordagem diacrónica do enquadramento legal das empresas públicas, é essencialmente sobre o diploma referente ao Regime Jurídico do Sector Empresarial Local, Lei 53-F/2006, de 29 de Dezembro, que recai a nossa interpretação, cruzando este diploma com outros cuja matéria tenha conexão.

Para a análise estatística dos dados relativos às empresas municipais estudadas utilizamos o programa da Microsoft Office Excel 2003 e calculamos a frequência de cada variável. A base de dados seleccionada foi o Ficheiro de Unidades Estatísticas do Instituto Nacional de Estatística, extracção de 09 de Julho de 2008. A amostra foi constituída pelas empresas municipais que integram na sua designação ou nos seus Códigos de Actividade Económica, referências a "desporto", "desportiva" ou "desportivo".

\section{Um novo sujeito de gestão pública local}

Como supra-mencionado, a Lei n. ${ }^{\circ}$ 53-F/2006, de 29 de Dezembro aprovou o Regime Jurídico do Sector Empresarial Local, que integra as empresas municipais, intermunicipais e metropolitanas (artigo 2. ${ }^{\circ}, \mathrm{n}^{\circ} 1$ ) e regula as condições em que os Municípios, Associações de Municípios ou Juntas Metropolitanas podem criar empresas dotadas de personalidade jurídica e de autonomia administrativa, financeira e patrimonial, com um dualismo organizativo: PRIVADO ou PÚBLICO.

No âmbito privado, como decorre do artigo $3 .^{\circ}$, n..$^{\circ}$ 1, alíneas a) e b), as empresas são constituídas nos termos da lei comercial, nas quais os municípios, associações de municípios e áreas metropolitanas possam exercer, de forma directa ou indirecta, uma influência dominante em virtude da detenção da maioria do capital ou dos direitos de voto, ou do direito de designar ou destituir a maioria dos membros do órgão de administração ou de fiscalização. Os municípios podem, por isso, constituir sociedades anónimas, sociedades por quotas e inclusivamente sociedades unipessoais. A denominação destas sociedades é acompanhada da indicação da sua natureza municipal, intermunicipal ou metropolitana (EM, EIM ou EMT).

Os órgãos sociais, que podem ser nomeados e exonerados pelos municípios ou pela assembleia geral são, nas sociedades anónimas o conselho de administração, a assembleia geral de accionistas, o fiscal único ou o conselho fiscal e nas sociedades por quotas, a assembleia geral e a gerência.

Ao nível público, as empresas são entidades empresariais locais, onde se incluem as "antigas" EM, constituídas ao abrigo do regime jurídico revogado pelo actual diploma, onde pontifica a tutela económico-financeira das Câmaras Municipais, através da aprovação dos planos de actividades e estratégico, orçamentos e contas, da fixação das dotações para o capital estatutário, subsídios e indemnizações compensatórias, da homologação preços ou tarifas a praticar pela empresa (artigo 39..$^{\circ}$ ).

Os municípios, associações de municípios e juntas metropolitanas detêm ainda poderes de superintendência sobre as entidades empresariais locais, previstos no regime anterior, através da emissão de directivas e instruções genéricas ao CA, autorização para a contracção de empréstimos ou definição do estatuto remuneratório dos membros dos órgãos sociais. À denominação das entidades empresariais locais deve ser integrado a indicação da sua natureza municipal, intermunicipal ou metropolitana (EEM, EEIM, EEMT) e os órgãos de administração e fiscalização das EEM, estruturam-se segundo as modalidades e com as designações previstas para as sociedades anónimas tendo as competências genéricas previstas na lei comercial.

A arquitectura do novel regime jurídico procura assim, aproximar o conceito de empresa municipal do conceito de empresa pública exposto no Regime Jurídico do Sector Empresarial do Estado 5 , ao prever a existência de empresas de direito público - as entidades empresarias locais (semelhantes às entidades públicas empresariais) onde se incluem as antigas empresas municipais constituídas nos termos da Lei n. ${ }^{\circ}$ 58/98, de 18/08 (v. art. $^{\circ} 34 .^{\circ}$, n. $^{\circ} 2$ ) - e introduzindo a possibilidade de se criarem empresas municipais de cariz comercial e societário, à semelhança do que já ocorria no sector empresarial do Estado. Também a disciplina na relação entre as entidades públicas e os parceiros privados no seio das empresas do sector empresarial local é reforçada, procurando evitar a discricionariedade que se tinha vindo a assistir na escolha dos parceiros privados pelos poderes públicos. 
Da constituição às funcionalidades da empresa municipal A constituição de uma empresa municipal é da competência da Assembleia Municipal, sob proposta da Câmara Municipal, sendo que, sob pena de nulidade e responsabilidade financeira a proposta de criação da empresa deve ser sempre precedida dos necessários estudos técnicos, nomeadamente do plano do projecto, na óptica do investimento, da exploração e do financiamento, demonstrando-se a viabilidade económica das unidades, através da identificação dos ganhos de qualidade, e a racionalidade acrescentada decorrente do desenvolvimento da actividade através de uma entidade empresarial, e ainda de um projecto de Estatutos (cf. artigos 8..$^{\circ}$, n. ${ }^{\circ} 1$, al. a) e 9. ${ }^{\circ}$, n. ${ }^{\circ}$ s 1 e 4 da lei em análise).

O mesmo ocorre nas decisões relativas à tomada de uma participação que confira ao município a influência dominante nestas empresas.

Quer a criação de empresas, quer a tomada de posição dominante, implicam a obrigatoriedade de comunicar tais factos à Inspecção Geral de Finanças, bem como à entidade reguladora do sector, com excepção das EEM ao qual este normativo não se aplica - art. ${ }^{\circ} 8^{\circ}$, n. $^{\circ} 2$.

Quanto às principais formalidades de constituição impõe-se que: $\left(\operatorname{art}^{\circ} 8^{\circ}\right.$, n. $^{\circ}$ s 3,4 e 5 e $\operatorname{art}^{\circ}{ }^{\circ} 33^{\circ}$ ): - O contrato constitutivo seja reduzido a escrito ou escritura pública (para celebração é competente o Notário privativo da Câmara);

- Seja comunicada a constituição ao Ministério Público;

- Seja publicada no Diário da República e num dos jornais mais lidos na área.

Em termos funcionais, é uma evidência, que as empresas municipais se têm assumido como um instrumento privilegiado de gestão autárquica e, nessa medida, articula os seus objectivos com os da Câmara Municipal, assegurando a necessária complementaridade e uma adequada interligação com o poder político municipal.

De facto, a possibilidade de agilizar e acelerar procedimentos nesta área de intervenção, que até às aludidas aberturas legislativas era da competência exclusiva da Câmara Municipal, coloca o Município ao nível de uma qualquer sociedade comercial na área dos serviços. Contudo as empresas municipais têm um objecto social prefigurado na lei, que apenas pode integrar:
— A gestão de serviços de interesse geral (artigo $\left.18 .^{\circ}\right)$;

- A promoção do desenvolvimento local e regional (artigo 21..$^{\circ}$ );

- A gestão de concessões (artigo $24 .^{\circ}$ ).

Matéria com especial acuidade diz respeito ao processo de relacionamento entre a Câmara Municipal e a empresa municipal, pois apesar de participadas e sob influência dominante dos municípios, as empresas municipais não se confundem com eles, constituindo-se como entidades juridicamente distintas, pelo menos num plano formal.

É o próprio regime jurídico que remete para o instituto do contrato, a regulamentação entre as duas entidades. Através de um contrato de gestão para as EM incumbidas da gestão de serviços de interesse geral e de um contrato-programa as que promovem o desenvolvimento local e regional (exigências determinadas pelos artigos $20 .^{\circ}$ e $23^{\circ}$ ).

E como bem enfatiza Pedro Gonçalves, não estamos perante um contrato "comum", mas antes como um "ponto de referência" das condições em que as partes se obrigam para a realização dos respectivos objectivos ${ }^{6}$, sendo a celebração do mesmo necessária ainda que não haja subsídios ou outras transferências financeiras provenientes das entidades participantes.

Referências expressas aos contratos de gestão e aos contratos-programa são feitas nas normas $20 .^{\circ}$ e $23 .^{\circ}$ do diploma em análise, retirando-se delas essencialmente quanto aos primeiros que definem pormenorizadamente o fundamento da necessidade e finalidade da relação contratual, bem como a eficácia e a eficiência que se pretende atingir com a mesma, concretizados num conjunto de indicadores ou referenciais que permitem medir a realização dos objectivos sectoriais. Estes contratos regulam ainda os termos em que se processam as transferências financeiras dos municípios, caso as empresas desenvolvam políticas de preços abaixo do custo, nos serviços prestados.

Os contratos-programa definem o seu objecto e missão, bem como as funções de desenvolvimento económico a desempenhar, deles constando obrigatoriamente o montante das comparticipações públicas subsídios e indemnizações compensatórias - que as EM têm direito a receber como contrapartida das obrigações assumidas. 
Nos termos dos referidos contratos, podem ser delegadas todas as competências necessárias para promover a gestão e exploração, a execução de obras de conservação e beneficiação dos espaços desportivos, nomeadamente pavilhões gimnodesportivos, polidesportivos e piscinas.

E no que tange às comparticipações financeiras recebidas como contrapartida advogamos que sejam assumidas pelas EM as seguintes obrigações: - A prática de preços sociais, isto é, preços diferenciados de acesso às piscinas, à utilização dos pavilhões e de outros equipamentos desportivos públicos, em função da condição social dos utentes; — Investimentos de rendibilidade não demonstrada, ou seja, o planeamento e a concretização de programas e actividades de promoção e desenvolvimento da prática e animação desportiva.

Aquelas comparticipações permitem colmatar ou, pelo menos, minimizar a perda efectiva que a aplicabilidade prática das medidas implica, ao nível do equilíbrio orçamental. Até porque as receitas das empresas se resumem quase em exclusivo àquelas que são provenientes da sua actividade.

Em função da experiência recente da política comercial implementada pelas empresas municipais de desporto e da análise a alguns elementos constantes dos respectivos instrumentos de gestão - balanço, demonstração de resultados e relatório sobre a execução anual dos orçamentos - o custo social suportado pelas mesma, restringe o seu crescimento e o grau de autonomia financeira, que no primeiro ano de actividade se situará entre os 10 e os $15 \%$.

A este propósito refira-se que, os estudos económico-financeiros prévios à constituição das empresas apontam para um período médio de seis anos para, ao nível de um índice de preços estável, aquelas poderem atingir o equilíbrio orçamental.

\section{Os recursos humanos}

Entre os múltiplos aspectos determinantes para a normal funcionalidade da empresa municipal, o dos recursos humanos assume particular relevância. E também neste capítulo a Lei n. ${ }^{\circ}$ 53-F/2006 preceitua claramente: $o$ estatuto do pessoal das empresas é o do regime do contrato individual de trabalho sendo a contratação colectiva regida pela lei geral (artigo $45 .^{\circ}$, n. ${ }^{\circ} \mathrm{s}$ 1 e 2).
No entanto, esta lei admite que os funcionários e agentes da administração pública, incluindo os do município, (...) podem exercer funções nas entidades do sector empresarial local em regime de afectação específica ou de cedência especial nas entidades do sector empresarial local, em regime de afectação específica ou de cedência especial, nos termos da legislação geral em matéria de mobilidade (artigo $46 .^{\circ},{ }^{\circ}{ }^{\circ}$ ).

A afectação específica está equiparada ao anterior conceito de destacamento e reporta "ao exercício de funções próprias da categoria e carreira do funcionário ou agente noutro serviço ou pessoa colectiva pública para satisfação de necessidades específicas e transitórias" determinada por despacho conjunto dos serviços, por iniciativa da pessoa colectiva ou a requerimento do funcionário. Esta afectação faz-se por períodos até 6 meses, prorrogáveis até ao limite de um ano e, salvo acordo em contrário, constitui encargo do serviço de origem, a remuneração das funções exercidas ${ }^{7}$.

A cedência especial ${ }^{8}$, que também se equipara ao conceito anterior de requisição, implica o acordo entre os serviços ou a pessoa colectiva pública e funcionário ou agente que tenha dado o seu consentimento expresso por escrito para o efeito, que neste regime vê suspenso o seu estatuto de funcionário ou agente da administração pública. Tal modalidade não tem limite de vigência temporal e a remuneração do funcionário ou agente é estabelecida nos termos do acordo de cedência, constituindo encargo da empresa municipal.

Esta cedência sujeita o funcionário cedido às ordens, instruções e poder disciplinar (à excepção da aplicação de penas disciplinares expulsivas) da empresa municipal.

$\mathrm{Na}$ cedência especial o funcionário ou agente tem ainda direito:

- À contagem, na categoria de origem, do tempo de serviço prestado, na empresa municipal;

- A optar pela manutenção do regime de protecção social da função pública devendo, no caso, a empresa municipal proceder ao pagamento da contribuição devida junto da Caixa Geral de Aposentações comparticipar nas despesas de administração da ADSE;

- A participar os concursos da função pública para os quais preencha os requisitos legais, cujo provimento na sequência do mesmo, implicará a extinção do 
acordo de cedência em vigor, sem prejuízo da celebração de uma novo acordo.

Ora, de acordo com estas balizas e de acordo com a existência de recursos humanos que já dispunham de uma relação contratual com o município, o quadro de pessoal inicial de uma EM poderá ser constituído do seguinte modo:

- Dispondo dos funcionários do Pelouro do

Desporto, aos quais numa fase de instalação se poderia aplicar o regime de afectação específica e, depois, numa fase de consolidação, com o seu assentimento, serem "requisitados" através de cedência especial à Câmara Municipal, porquanto mantêm vínculo à função pública;

- Retendo os particulares que, trabalhando para o município, se mantinham num regime de prestação de serviços e podem agora outorgar com a empresa, um contrato individual de trabalho, tornando mais efectiva a sua colaboração;

- Permitir aos funcionários que laboravam nos equipamentos municipais ou em certas actividades já existentes, e que dispunham de um vínculo precário com o município, a celebração, em alternativa, de contratos a termo com a empresa municipal.

A estes deverão juntar-se, contratados $a b$ initio, profissionais e técnicos qualificados que constituíam a espinha dorsal das áreas administrativa, financeira e funcional da empresa, onde se incluem naturalmente os recursos humanos específicos da área de actividade da empresa municipal, nomeadamente licenciados em Educação Física e Gestão do Desporto.

A economia funcional, de custos e de recursos, deverá começar no próprio órgão de administração que, numa fase de implantação da empresa, deverá ser reduzido e acumular as funções de chefia de primeira linha.

A possibilidade de se criar um quadro de pessoal de raiz, permite desde logo:

- A existência de um novo estatuto remuneratório, com valores mais atractivos - superiores àqueles que são praticados numa Câmara Municipal, mas também mais justos, porque premeiam o trabalho efectivo de cada um. À remuneração base e ao subsídio de refeição pode acrescer, entre outros factores, conforme os casos, subsídio de turno, créditos pela isenção de horário e assunção de chefias;

- A elaboração de um nova metodologia na promo- ção e progressão na carreira, relevando o mérito em detrimento da antiguidade;

- Extinguem-se as horas extra com a fixação de horários por turnos nos equipamentos desportivos, com a atribuição do respectivo subsídio determinado legalmente;

- A criação de um sistema de avaliação de desempenho para efeitos de promoção e classificação dos funcionários, tais como a fixação de patamares de desempenho, a relação no local de trabalho e com os utentes, o respeito pelos procedimentos e cultura da empresa;

- Implementação de um adequado programa de formação profissional, com selecção criteriosa quer dos funcionários, quer das acções a promover ou a participar; - Relação de proximidade das chefias com os funcionários de base, eliminando o carácter de abstracção em que funda o poder tradicionalmente hierarquizado de uma Câmara Municipal.

\section{Empreitada e aquisição de bens e serviços}

No que respeita a empreitadas e aquisição de bens e serviços, até 1 de Julho de 2008, data do início da vigência do Código dos Contratos Públicos (CCP) ${ }^{9}$, não existia qualquer regra imperativa que obrigasse as empresas municipais à abertura de concurso público para adquirir bens ou contratar serviços, regendo-se aquelas pelo Princípio da Liberdade Contratual, definido pelo artigo $405^{\circ}$ do Código Civil, o qual dispõe que dentro dos limites da lei, as partes têm a faculdade de fixar livremente o conteúdo dos contratos, celebrar contratos diferentes dos previstos e neste código e incluir nestes as cláusulas que lhes aprouver. No entanto, as empresas municipais, por mera cautela ou adoptavam procedimentos de controlo próprios, organizados em função do montante da despesa a realizar, que para além de agilizarem os procedimentos, asseguravam também a transparência na tramitação dos processos de contratação para aquisição de bens ou de fornecimento de serviços com autorizações internas ou com consulta prévia a um número mínimo de fornecedores, ou seguiam o regime de aquisição de bens e serviços vigente na administração pública, aprovado pelo Decreto-Lei n. ${ }^{\circ}$ 197/99, de 8 de Junho. 
Também a abertura de concursos e a adjudicação de empreitadas para a construção de equipamentos desportivos, não obstante se tratar de uma área sem grande tradição ou actividade relevante ao nível da história recente das empresas municipais de desporto, não era pacífica a equiparação destas ao sector público do Estado, e a consequente aplicabilidade do Decreto-Lei n. ${ }^{\circ}$ 59/99, de 2 de Março, que regulamentava o regime jurídico de empreitadas de obras públicas (al. g) do n. ${ }^{\circ} 1$ do artigo $3 .^{\circ}$ ).

Ora, o novo regime jurídico de contratação pública, para além de revogar estes diplomas, dissipa todas as dúvidas, enquadrando as empresas municipais como entidades adjudicantes, no âmbito da respectiva aplicação. Neste particular, embora adoptando as regras vigentes na administração pública, é manifesto que, mesmo considerando o cumprimento de prazos e formalismos legais, quer os processos de decisão, quer a funcionalidade da estrutura de uma empresa municipal, permitirão uma maior celeridade tanto para a aquisição de bens e serviços como para a execução das empreitadas.

\section{Organização financeira, centros de custos e preços sociais}

Este modelo empresarial aplicado à realidade do desporto, tal como outros sectores cujo objectivo seja rentabilizar recursos, pretende implementar processos rigorosos e padronizados de gestão financeira e contabilística que clarifiquem como são gastos os dinheiros públicos.

A transferência dos equipamentos desportivos implica a celebração de novos contratos para aquisição e fornecimento de serviços externos, devendo proceder-se a uma consulta prévia e alargada aos mercados especializados, com a posterior criação de um centro de custos para cada um dos equipamentos existentes.

Os encargos, que anteriormente, ao nível do município figuram como custo global, nunca identificados ou insuficientemente justificados (ex. da factura apresentada pela PT à Câmara Municipal contém normalmente um infindável rol de números de telefone, sem indicação, nem da origem, nem dos acessos), passarão a ser contabilizados individualmente, o que permitirá uma redução substancial ao nível das despesas correntes.
Os orçamentos, os custos e as receitas, serão contabilizados e apresentados, equipamento a equipamento, conhecendo-se, a todo o tempo, quais os encargos que cada espaço apresenta em electricidade, telecomunicações, recursos humanos, produtos de higiene, limpeza e conservação, água, gás ou seguros. Tais montantes eram normalmente liquidados num enorme lençol de preços e de serviços, cujos custos a Câmara Municipal nem tinha a possibilidade de detalhar ou comparar.

A mesma lógica se aplicará à programação das actividades, que são planeadas com base na elaboração de um plano de meios: especificação parcelar dos encargos (entre outros, inserções nos jornais, spots rádio ou TV, custo de flyers, outdoors e cartazes, meios de organização, alimentação e alojamento), que tanto serve para aferir da disponibilidade orçamental para a realização dos eventos, como para controlar os custos e evitar derrapagens na realização da despesa. Atendendo à procura cada vez maior de espaços para praticar desporto pelo cidadão anónimo, para a sua manutenção e lazer, ou pelas associações, para as suas actividades desportivas federadas e não federadas, podem introduzir-se inovações ao nível das taxas a praticar pelas empresas municipais de desporto no acesso aos equipamentos desportivos, tendo em conta que:

- A necessidade de disciplinar a utilização dos espaços vai para além da adopção dos preços sociais, e o custo pode sobretudo ser definido em função da localização geográfica dos equipamentos e/ou pela condição social dos utentes que os utilizam. Deste modo poderão utilizar os pavilhões municipais, com equidade, os clubes federados, os particulares ou os grupos organizados informalmente, no decurso da época desportiva, considerada entre 1 de Setembro e 30 de Junho do ano seguinte.

Estas medidas permitem compreender o alcance dos ganhos de gestão da empresa, no controle dos encargos de exploração, na rentabilidade dos equipamentos ou na eficiência e qualidade dos serviços prestados. Tendo em consideração o referido horizonte de seis anos, para que esta atinja um equilíbrio entre as receitas e as despesas, as empresas municipais, numa fase posterior à sua consolidação enquanto estrutura, terão na comercialização e venda de espaços para publicidade estática, nos pavimentos de 
jogo, tabelas laterais e paredes dos pavilhões ou nos tectos, fundos e paredes das piscinas um manancial de fontes de receita ainda por explorar.

$\mathrm{Na}$ mesma esteira, poderão ser consideradas as cessões de exploração dos bares daqueles espaços desportivos, através da realização de concurso público para a respectiva adjudicação.

\section{Fiscalidade}

Mesmo enfermando de alguma polémica, porque estamos perante uma nova realidade, a regra que seguem as empresas municipais vai no sentido de que tudo quanto sejam proveitos, nomeadamente as receitas de uma actividade comercial ou da prestação de um serviço (bilhetes de acesso à piscina ou a taxa de utilização do pavilhão) são tributados em sede de IVA, que a empresa tem de arrecadar e entregar ao Estado.

A receita fica prejudicada, diminuindo na proporção directa do imposto liquidado, uma vez que antes a Câmara Municipal, estando isenta daquela tributação, arrecadava o preço por inteiro, que agora é fraccionado, numa parte correspondente ao proveito e outra relativa ao imposto indirecto que se cobra no próprio preço.

Temos de ressalvar, o que também não é pacífico admitir (facto questionado por alguns ROC's no pleno exercício de funções), os subsídios e as indemnizações compensatórias que, funcionando como contrapartida da obrigação de realizar investimentos de rendibilidade não demonstrada ou da adopção de preços sociais $^{10}$ não estão, na nossa opinião, sujeitos à liquidação daquele imposto.

Talvez não seja despiciendo equacionar a contratualização de uma prestação de serviços na área da fiscalidade com uma empresa especializada. Os custos são reduzidos e os ganhos na operacionalização da empresa municipal parecem evidentes.

$\mathrm{Na}$ liquidação de IRC, imposto sobre o rendimento de pessoas colectivas, incluindo o pagamento especial por conta, o enquadramento não suscita polémica e a empresa municipal é equiparável a uma sociedade comercial do sector privado.

Fisionomia geral das empresas municipais de desporto No sentido de cumprir o segundo objectivo deste trabalho, incidiremos seguidamente a nossa investigação sobre alguns aspectos caracterizadores das empresas municipais de desporto, tendo em perspectiva, em pesquisas futuras aprofundarmos outras matérias, nomeadamente as estruturas orgânicas destas entidades, a organização dos programas de desporto que apresentam, a relação contratual que celebram com os sócios e a relação que estabelecem com empresas congéneres.

Para tal, importa, desde já, clarificar que, quando nos referimos a "Empresas Municipais de Desporto", fazemo-lo atendendo às Empresas Municipais que têm, na sua designação ou nos seus Códigos de Actividade Económica (CAE), referências a "desporto", "desportiva" ou "desportivo".

$\mathrm{Na}$ recolha dos dados que nos interessam de momento, recorremos a duas fontes, designadamente: a publicação da Direcção Geral das Autarquias Locais, "ADMINISTRAÇÃO LOCAL em números 2005", e o Instituto Nacional de Estatística ${ }^{11 .}$ Alertamos para o facto de que, correspondendo à exigência legal ínsita no $n .^{\circ} 7$, do artigo $8 .^{\circ}$, da já referida Lei no $53-\mathrm{F} / 2006$, a Direcção Geral das Autarquias Locais mantém no seu sítio ${ }^{12}$ uma lista actualizada das entidades do sector empresarial local, da qual constam já 208 empresas municipais, contra as 194 que constam do ficheiro do INE. No entanto, apesar da discrepância incompreensível de dados indicados pelas fontes públicas, optamos por utilizar a informação fornecida pelo INE, pois disponibiliza mais dados caracterizadores, permitindo uma análise mais aprofundada, ao contrário da lista da Direcção Geral das Autarquias Locais, onde apenas constam as designações e os contactos das empresas municipais.

Empresas municipais: quantas são e onde se localizam? Começamos por analisar o número e a distribuição por distrito das empresas municipais na sua generalidade e verificamos que, em 2008 existem, no Ficheiro de Unidades Estatísticas anteriormente referido, 194 empresas municipais, correspondendo 168 às existentes no continente e 26 às existentes nas regiões autónomas.

Conforme podemos observar no gráfico 1 , surgem nos lugares cimeiros da lista os distritos de Porto e Lisboa, com 26 e 24 empresas municipais respectivamente, imediatamente seguidos pela Região Autónoma dos Açores, com 20 empresas municipais. 


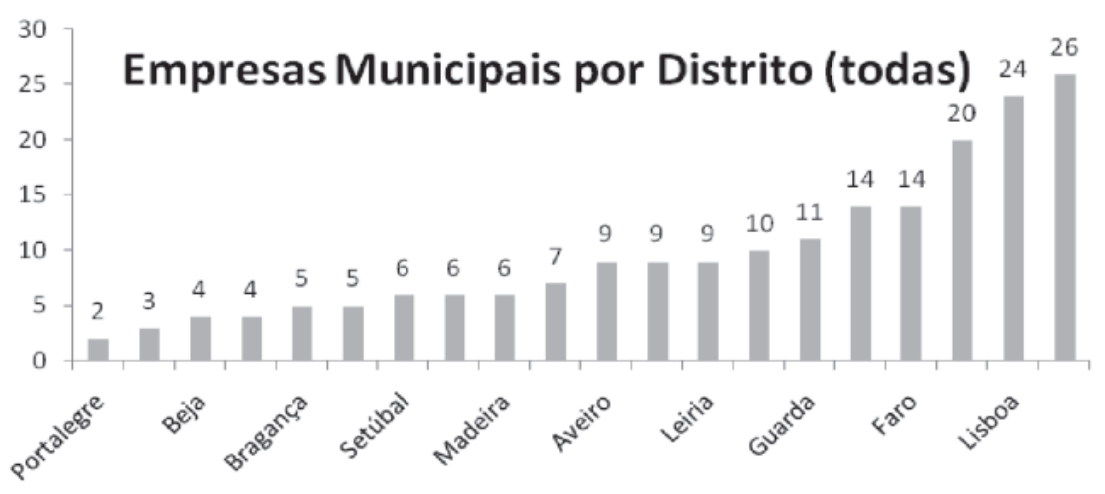

Gráfico 1.

Empresas municipais por distrito.

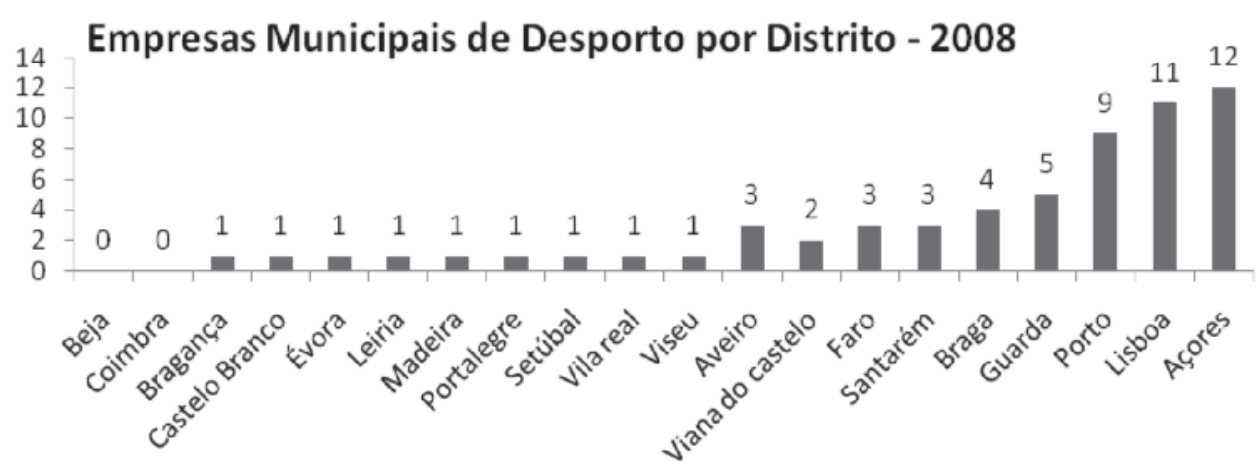

Gráfico 2. Empresas municipais de desporto por distrito

\section{Empresas Municipais de Desporto por Ano de Constituição}

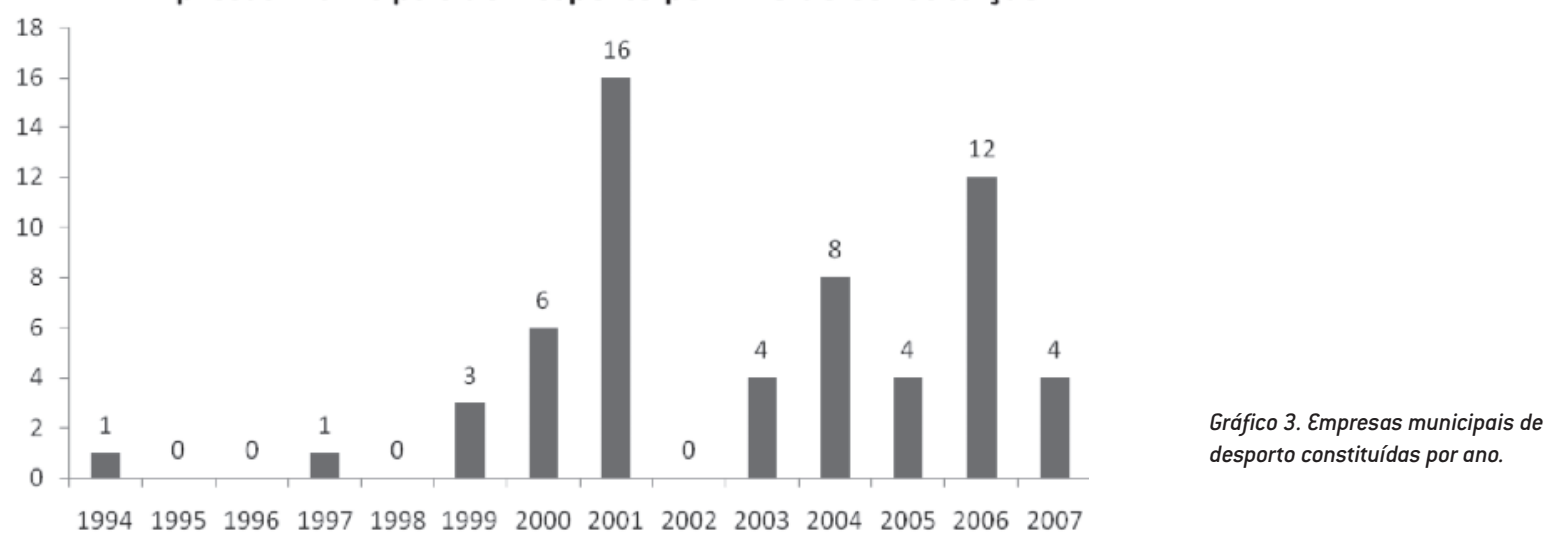

Empresas municipais de desporto: quantas são. onde se localizam e quando se constituíram? Das 194 empresas municipais, 31\%, que correspondem a 61 empresas, têm no seu CAE, actividades relacionadas com Desporto, de acordo com os critérios de inclusão antes referidos de existência dos termos "desporto", "desportiva" ou "desportivo" na designação da empresa ou nos Códigos de 
Actividade Económica. Para uma maior clarificação deste enquadramento, deverão ser analisados os instrumentos de gestão destas empresas, como sejam os planos e relatórios de actividades.

Ao analisarmos a distribuição geográfica das empresas municipais do desporto, constatamos que a tendência se mantém, pelo que são os Distritos de Lisboa e Porto que apresentam o maior número de empresas municipais do Desporto, no continente. A Região Autónoma dos Açores apresenta também aqui um número muito elevado de empresas municipais de desporto, sendo que das 12 empresas municipais existentes, 8 têm desporto no seu CAE principal e as restantes, apresentam esta característica na designação da empresa ou no CAE secundário.

Nos distritos de Beja, Coimbra e Setúbal, não está identificada nenhuma empresa municipal de desporto. No que se refere ao ano de constituição, identificamos 3 anos bastante férteis na criação de empresas municipais do desporto: 2001, ano em que se registou a constituição de 16 empresas municipais de desporto; 2004, ano em que se constituíram 8 empresas desta natureza e finalmente $2006 \mathrm{com}$ a criação de 12 novas entidades do género. As razões destes momentos altos, serão alvo de investigação futura, pois parecem estar relacionados com momentos políticos e desportivos importantes como as eleições autárquicas, o surgimento de nova legislação ou a realização do Euro 2004.

\section{Qual a sua actividade económica principal?}

Embora já se tenha constatado que a existência do Desporto no Código de Actividade Económica, não é factor suficiente para afirmar que uma dada empresa municipal se dedica realmente aquela actividade, julgamos que a existência do Desporto no CAE principal da empresa poderá ajudar a clarificar esta questão. Assim, constatamos que, das 61 empresas municiais do Desporto que fazem parte desta análise, cerca de $40 \%$ (24) têm como CAE principal a "Gestão de Instalações Desportivas" e, quase $30 \%$ (18) incluem Desporto no CAE principal, perfazendo $70 \%$.

Nas restantes 19 (31,15\%) encontramos o desporto no CAE Secundário.

\section{Quantas pessoas têm ao serviço?}

Outro dado importante nesta matéria é o número de pessoas que constituem as empresas. Neste ponto, os dados disponíveis apresentam elevada percentagem de valores não especificados, o que dificulta a análise, mas revelam que mais de metade das empresas municipais, têm menos de 50 trabalhadores. O facto de $25 \%$ das empresas terem menos de 10 trabalhadores será também um dado suficientemente importante para análise futura.

\section{Qual o seu volume de negócios?}

Por fim, e no que se refere ao volume de negócios, podemos também verificar uma elevada percentagem de valores não especificados.

Das empresas cujos dados conhecemos, constatamos que mais de metade apresenta um volume de negócios inferior a 1.500.000,00€ (um milhão e quinhentos mil euros) e cerca de $37 \%$ destas, atingem apenas o escalão dos 500.000,00 (quinhentos mil euros).

\section{NOTAS CONCLUSIVAS}

A adopção do modelo empresarial para a gestão da actividade económica relativa ao desporto está longe de ser tomada como pacífica e tem dividido opiniões, entre os que se vinculam à solução e os que a condenam, por representar, por um lado, a autonomia das decisões públicas ou, por outro lado, a menoridade do próprio Estado na matéria.

Primeiro, a Lei $\mathrm{n}^{\circ}$ 58/98, de 18 de Agosto e depois o regime jurídico do sector empresarial local, aprovado pela Lei $n^{\circ}$ 53-F/2006, de 29 de Dezembro, vieram dotar os municípios de um instrumento há muito desejado, com o condão de ultrapassar os constrangimentos característicos e inerentes às pesadas máquinas administrativas do Estado, pouco céleres no tratamento de um vasto conjunto de variáveis que estão presentes na prestação de serviços na área desportiva, nomeadamente a gestão de instalações e espaços desportivos, geradores de uma elevada diversidade de valências para a actividade física e desportiva.

Efectivamente, a empresa municipal, dotada de autonomia financeira, administrativa e patrimonial, permite uma nova fórmula para organizar o serviço público, conducente a uma gestão mais eficaz e com níveis crescentes de qualidade, que garantem a gestão, pelo Estado, do património público reforçando os desígnios da intervenção e da rentabilidade social que este deve salvaguardar, garantir e regular, excluindo o recurso à privatização. 
Empresas Municipais de Desporto por Actividade Económica Principal

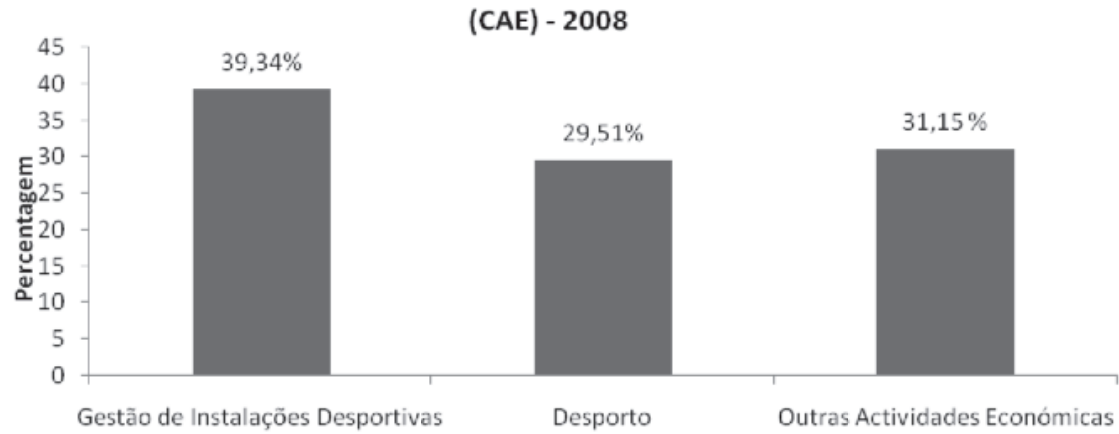

Gráfico 4. Empresas municipais de desporto por actividade económica principal.

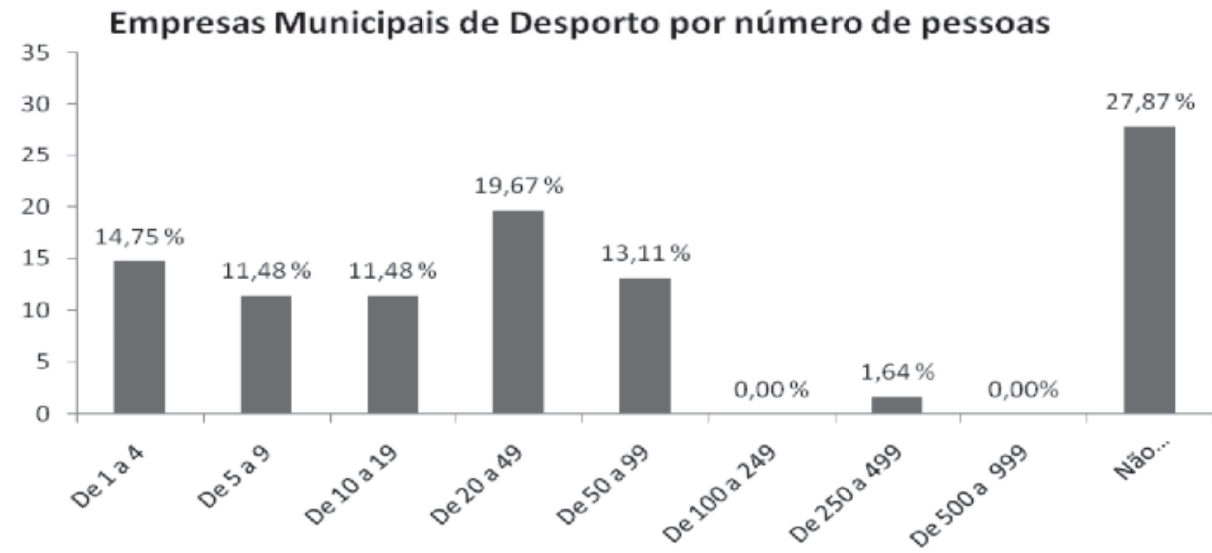

Gráfico 5. Empresas

municipais de desporto por número de trabalhadores

\section{Empresas Municipais de Desporto por escalão de Volume}

$$
\text { de Negócios }
$$

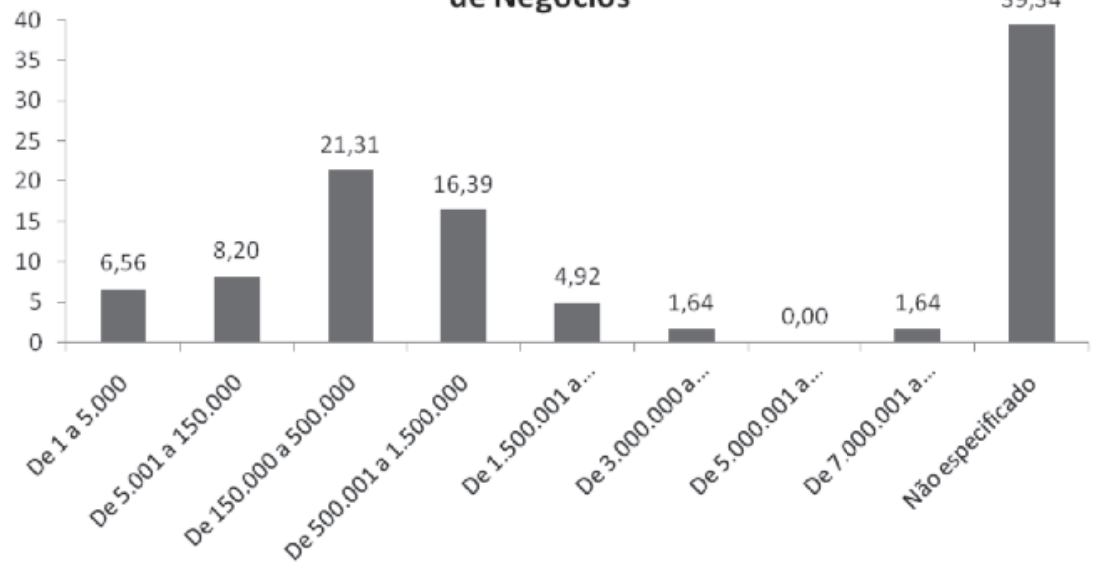

Gráfico 6. Empresas municipais de desporto por volume de negócios. 
No conjunto das questões que suscitam a falta de vocação da administração local para a gestão directa destas instalações, ou pelo menos a debilidade de mecanismos para o fazer da forma mais adequada, releva a dificuldade no recrutamento de recursos humanos especializados, nomeadamente com qualificações, cujo reconhecimento ainda é recente - cursos e licenciaturas em educação física e gestão do desporto. Acresce ainda que, muitas autarquias, fruto do grau de endividamento, se aproximam perigosamente do limite legal permitido para os custos com o pessoal $60 \%$ do valor global do orçamento - facto que, na maior parte dos casos, condiciona a realização de novos investimentos, impede a gestão directa dos equipamentos e promove o incremento de processos de privatização das instalações desportivas municipais, sem consistência e sustentabilidade.

A autonomia administrativa das empresas municipais, ao contrário da administração pública, que manifestamente não tem dado resposta às necessidades específicas do sector, permite a organização de um quadro de pessoal, com carreiras e categorias profissionais, perfeitamente ajustado ao seu objecto social e às reais necessidades e características do mercado que serve.

No entanto, para que uma empresa municipal possa potenciar o desenvolvimento do movimento desportivo de um município, é necessário respeitar duas premissas fundamentais, quais sejam a de que aquela resista à tentação de não se constituir como concorrente do associativismo desportivo local e que, nas suas atribuições, não reproduza uma duplicação das competências próprias dos serviços de desporto da autarquia. Ao contrário, a criação da empresa municipal deverá abrir caminho para um maior empenhamento das Divisões de Desporto das autarquias na prossecução das suas competências próprias e exclusivas, nomeadamente apoio e incentivo ao associativismo, estudo e planeamento de programas de desenvolvimento e construção de novos equipamentos desportivos, in casu, de acordo com o que vertem o $\operatorname{art}^{\circ} 64^{\circ}, \mathrm{n}^{\circ} 4$, alínea b), da Lei no 169/99, de 18 de Setembro. Mas, no fim, tal como no princípio, subsiste uma pequena grande dúvida. Porque é que o legislador, interpretando as dificuldades de ordem prática, foi em busca de agilizar procedimentos, criando um novo modelo de gestão?
Porquê e para quê fazê-lo coexistir, quer com a pesada e infuncional máquina administrativa do Estado, quer com regras e procedimentos de gestão que estão "fora do prazo de validade"?

Porque não, e quiçá com maior eficácia e economia de meios e recursos, disciplinar a desburocratização dos procedimentos do próprio Estado, no âmbito de uma verdadeira reforma da administração pública? Estas dúvidas persistem fundadas na convicção de que a Administração, mesmo quando revestida de trajes privados, não pode nunca deixar de estar vinculada à observância de princípios, tão bem clarificados por Maria João Estorninho, como o Prossecução do Interesse Público, o da Legalidade, ou o da Vinculação aos Direitos Fundamentais(5). Dito de outro modo, parece-nos crucial que entendamos que qualquer que seja a forma jurídica para a gestão do desporto no município, esta tem de respeitar inevitavelmente o tipo de actividade a desempenhar pela Administração Pública, donde se torna evidente que a celeridade e a eficácia pretendidas através da adopção da gestão empresarial não se obtenham à custa da diminuição ou inobservância dos princípios acima relembrados.

\section{CORRESPONDÊNCIA}

\section{Maria José Carvalho}

Faculdade de Desporto da Universidade do Porto

Rua Dr. Plácido Costa, 91 - 4200.450 Porto Portugal

E-mail:mjc@fade.up.pt 


\section{NOTAS}

${ }^{1}$ A Lei n. ${ }^{\circ} 79 / 77$, de 25 de Outubro, no seu artigo $48 .^{\circ}$, n. ${ }^{\circ} 1$, al. o), atribuía à assembleia municipal a competência para autorizar o município a "formar empresas municipais". A mesma perspectiva foi seguida no Decreto-Lei n. ${ }^{\circ}$ 100/84, de 29 de Março ao reiterar no artigo $39 .^{\circ}$, n. $^{\circ} 2$, al. g), a competência da assembleia municipal para autorizar o município "a criar empresas públicas municipais".

2 Também outros autores, como EUGÉNIO ANTUNES, As autarquias locais e a nova gestão pública - as empresas públicas municipais e a prestação de contas, Tese de mestrado, ISCTE, 2003; JoÃo

PACHECO DE AMORIM, As empresas públicas no direito português - em especial, as empresas municipais, Coimbra, Almedina, 2000, ou CARLOS BAPTISTA LOBO, "A função de actuação económica do estado e o novo regime jurídico do sector empresarial do Estado e das empresas públicas municipais", in Eduardo Paz Ferreira (org.), Estudos sobre o Novo Regime do Sector Empresarial do Estado, Coimbra, Almedina, 2000, pp. 241-255, haviam tecido criticas ao instituído na Lei n. ${ }^{\circ} 58 / 98$. Destaque para outras análises a este diploma em auditorias e pareceres do Tribunal de Contas, designadamente: Relatório de Auditoria 5/2007 2. ${ }^{\text {a }}$ Secção - Auditoria Temática aos Vencimentos e Remunerações Acessórias dos Titulares do Órgão de Gestão das Empresas Municipais 2003-2004; Relatório de Auditoria no 24/2005 - $2^{\text {a }}$ Secção Auditoria à EPMES - Empresa Pública Municipal de Estacionamento em Sintra, EM; Relatório de Auditoria $\mathrm{n}^{\circ}$ $11 / 2005$ - 2 a Secção Auditoria ao Exercício de 2003 da HPEM - Higiene Pública, EM.; Relatório de Auditoria no 4/2005 - $2^{\text {a }}$ Secção EMSUAS - Empresa Municipal de Serviços Urbanos de Alcácer do Sal, EM - Exercício de 2002. Por parte da

Procuradoria-geral da República registemos também as análises àquele regime nos Pareceres n. ${ }^{\circ} 83 / 93$, de 10 de Maio de 1995, n. ${ }^{\circ}$ 02/2000, de 06 de Abril de 2000, n. ${ }^{\circ} 77 / 2002$, de 13 de Fevereiro de 2003 e n. ${ }^{\circ}$ 10/2003, de 15 de Maio de 2003, cf. podem ser consultados em texto integral disponível em http://www.dgsi.pt.

${ }^{3}$ Em complemento foram publicados diplomas com importantes orientações sobre a gestão deste sector, em especial a Lei das Finanças Locais (Lei n. ${ }^{\circ} 2 / 2007$, de 15 de Janeiro) e o Estatuto do Gestor Público (Decreto-Lei n. ${ }^{\circ} 71 / 07$, de 27 de Março). Referência ainda para os princípios de bom governo das empresas do sector empresarial do Estado ínsitos na Resolução do Conselho de Ministros n. ${ }^{\circ}$ 49/2007, de 27 de Março. ${ }^{4}$ Cf. artigo $5^{\circ}$, nos 1 e 2 da Lei n. ${ }^{\circ} 53-F / 2006$, de 29 de Dezembro, norma que estatui como objecto social obrigatório destas empresas a exploração de actividades de interesse geral, a promoção do desenvolvimento local e regional e a gestão de concessões, como melhor analisaremos adiante.

${ }^{5} \mathrm{Cf}$. artigo $3 .^{\circ}$ do Decreto-Lei n. ${ }^{\circ} 558 / 99$, de 17 de Dezembro, diploma que sujeito a alteração pelo Decreto-Lei n. ${ }^{\circ}$ 300/2007, de 23 de Agosto.

${ }^{6}$ Como na nota 6 , pp. $173-178$

${ }^{7}$ Cf. o artigo $8 .^{\circ}, n^{\circ}$ s 1,2 e 4 da Lei n. ${ }^{\circ} 53 / 2006$, de 7 de Dezembro, que estabelece o Regime comum de mobilidade entre serviços dos funcionários e agentes da Administração Pública. ${ }^{8}$ Ver a este respeito o artigo $9 .^{\circ}$ da lei referida na nota anterior. ${ }^{9}$ Aprovado pelo Decreto-Lei n. ${ }^{\circ} 18 / 2008$, de 29 de Janeiro, que estabelece a disciplina aplicável à contratação pública e o regime substantivo dos contratos públicos.

${ }^{10}$ Ver artigo $20 .^{\circ}$, n. ${ }^{\circ} 4$ e artigo $23 .^{\circ}$, n. ${ }^{\circ} 2$ da Lei n. ${ }^{\circ}$ 53-F/2006, de 29 de Dezembro.

${ }^{11}$ Solicitamos ao Instituto Nacional de Estatística (INE) uma extracção de dados, em 24 de Junho de 2008, do Ficheiro de Unidades Estatísticas (FUE), que nos foi facultada em 09 de Julho de 2008.

${ }^{12}$ Endereço electrónico http://www.dgaa.pt, consultado em 9 de Julho de 2008.

\section{REFERÊNCIAS}

1. Amorim J (2000). As empresas públicas no direito português em especial, as empresas municipais. Coimbra: Almedina.

2. Antunes E (2003), As autarquias locais e a nova gestão pública - as empresa públicas municipais e a prestação de contas, Tese de mestrado, ISCTE.

3. Carvalho MJ (2007). Os elementos estruturantes do regime jurídico do desporto profissional em Portugal. Dissertação de Doutoramento apresentada à Faculdade de Desporto da Universidade do Porto.

4. Direcção Geral das Autarquias Locais (2006). Administração Local em Números. Lisboa.

5. Estorninho MJ (1999). A fuga para o direito privado-contributo para o estudo da actividade de direito privado da Administração Pública. Coimbra, Almedina.

6. Gonçalves, P. (2007). Regime Jurídico das Empresas Municipais. Coimbra, Almedina.

7. Lobo, C. (2000). “A função de actuação económica do estado e o novo regime jurídico do sector empresarial do Estado e das empresas públicas municipais", in Eduardo Paz Ferreira (org.), Estudos sobre o Novo Regime do Sector Empresarial do Estado, Coimbra, Almedina, pp. 241-255. 